\title{
Techno-economic assessment of recycling acidic sludge project of reprocessing industries to value-added gaseous products using Plasmatron
}

\author{
Malek Hassanpour* ${ }^{(\mathbb{D}}$ \\ Department of Environmental Science, UCS, Osmania University, Hyderabad, Telangana State, India
}

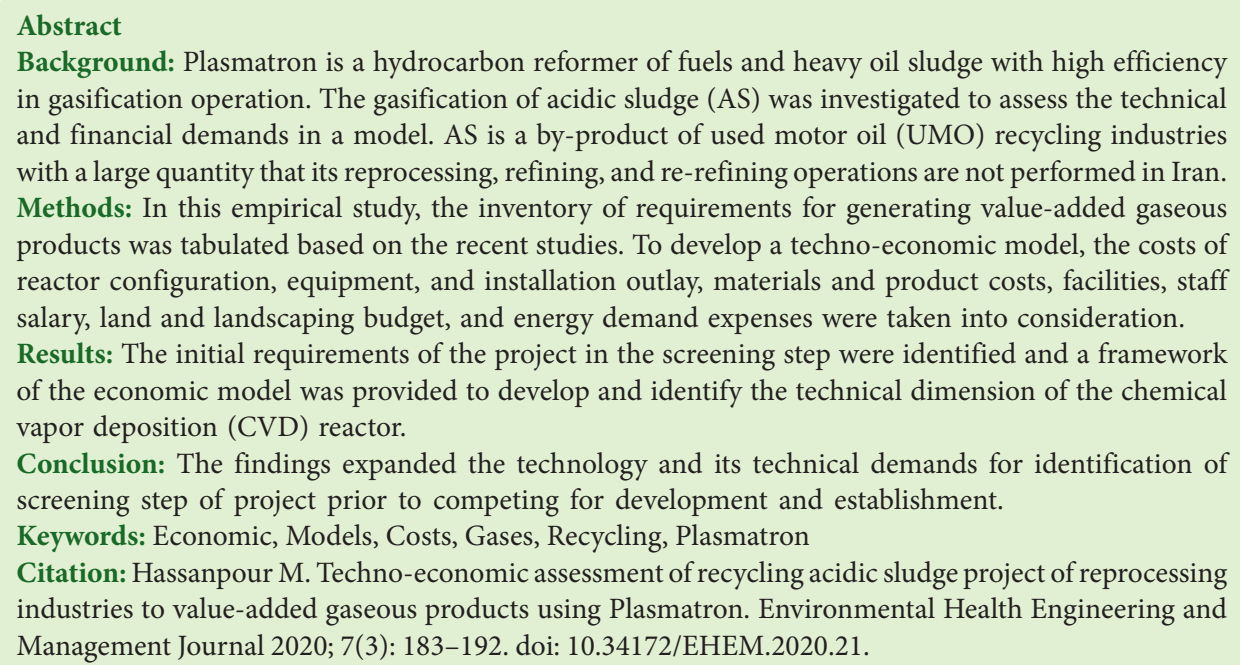

Article History:

Received: 5 May 2019

Accepted: 29 July 2020

ePublished: 15 September 2020

\section{Introduction}

According to the reports published by the national Iranian industries organization (NIIO), there are currently more than 250 used mineral oils (UMOs) reprocessing plants that are operating across the country. The main method for managing UMO is collecting and recycling in Iran and over the world. According to recent studies, at least 600 tons of base motor oil is produced per 1000 tons of UMO recycled. While 6000 tons of crude oil is needed to produce the same amount of motor oil, which illustrates the importance of the UMO recycling operation. Sulfuric acid/clay technology is used as the UMO reprocessing method in Iran. UMO recycling operation conducted by acid/clay technique is carried out through dehydration, heating, along with acidification and finishing of the UMO. This process produces 15 barrels of acidic sludge (AS) from 100 barrels of the UMO as waste materials. Globally, both oil (petroleum) generation and consumption are over 80-100 million barrels daily, and approximately 3\%-7\% of the processed oil is released as oily waste or sludge waste. But it is not exactly the same as AS identity. Therefore, the quantity of UMO and AS generated are very impressive. AS is posed as a hazardous waste material with the potential to generate carcinogenic effects (1).

The ruling strategy enacted to develop and support Iranian industries is going on to comprise the sustainability of small industries in private and semi-private configurations. The Iranian government enacted very strict regulations for protecting the environment against any pollution arises from industries states. Therefore, the stockholders forced and also encouraged to follow the existing rules. AS deals with serious challenges in both environment and the UMO reprocessing industries due to the large quantities released. Recent studies have attempted to increase knowledge towards sustainable development and solve the problems emerged in the AS management strategies. By producing new type of bitumen and trying to allocate the AS in a mix with residual of vacuum bottom of refineries, it is claimed that management of hazardous waste is improved. In the civilized nations, the main strategy for handling AS is based on changing the UMO treatment technology towards employing new technologies along 
with no separation of the UMO stream. UMO collection is integrated with used lubricants and underwent re-refining and re-generation processes instead of reprocessing techniques. But in Iran, it is preferred to use in-source management and handle UMO stream as in-situ and in location due to the existence of UMO recycling industries in cities and provinces and high outlays for transportation to refineries which are mostly located in the south of Iran. On the other hand, refineries also encountered high outcomes of AS because of employing the same procedure for crude oil treatment, therefore, the best strategy is supporting private or semi-private UMO recycling industries. The main advantages of this strategy are promoting job opportunities and conducting small industries towards growth and sustainable development. Although new technologies employed in most civilized nations are costly but they produce high-quality products with very low AS outcomes even to zero level emission of AS in UMO recycling techniques. In-situ management of AS demands low costs and also needs no change in recycling technologies. However, any modification in the structure of acid/clay technology will also increase the handling outlays. The acid/clay technology is dominant in handling the UMO stream with high-quality oil products in many under-developed nations. Also, the quality of products can be modified and amended by existing additives (2-4).

Recent studies on the AS management have resulted in employing the biological processes. The re-refined AS removal technique via aerated in-vessel composting with various ratios in 70 days was investigated. But, the removal efficiency did not meet the allowable standards. Therefore, the findings proved that biological methods cannot be reasonable practices in managing AS (5). In another research, the refined AS was used to modify the vacuum bottom properties. The findings showed that the use of various percentages of AS lead to the increase of the resin and asphaltene concentrations, ductility, mechanical properties, elastic modulus, thermal stability, durability properties, and decrease of the aging characteristic of bitumen. So, this research proved the important role of AS as an additive in improving bitumen properties in parallel with author's studies (6).

Pyrolysis and simple methods of combustion and gasification are not very cost-effective method and they demand a relatively high budget for the AS removal processes as well as wasting a valuable resource and secondary pollutants dissipation challenges. Also, the methods need a high level of energy consumption for removal of AS (7). Nowadays, the relevant and dominant technology that is used as a solution for managing AS is Plasmatron reactor. The utilization and application of plasma technology in a variety of sciences is novel. Plasmatron is a novel technology for converting heavy and light hydrocarbon-based materials to useful gaseous products. The simplicity of use, high efficiency, and its low power and energy consumption paved the way for a variety of applications. In the best management program, AS can be converted to value-added gaseous products, which are also employed in the finishing process in the UMO recycling technologies. $\mathrm{H}_{2}$ is widely used for the UMO treatment and there is a heavy demand for its applications. But this technology needs considerations in terms of techno-economic view.

A techno-economic assessment (TEA) involves allocating the whole inventory of requirements in the industry. The main demands are devoted to materials and energy streams, facilities and equipment and their installation, reactor configuration, land area required, etc. But, the framework defined, falls in the dimension of a project when it is going to develop before the construction step. The project claims that there are many steps for getting the required licenses from industries organization and the Environmental Protection Agency (EPA). The environmental impact assessment (EIA) is a defined plan that include the project identification steps in accepting and approving projects. The EIA was set by a few important steps such as project identification, screening, public involvement, decision making step, approval/disapproval of the project, and even post-EIA in Iran. The EIA also requires a TEA that explains the efficiency and financial aspects of a project to move towards full-scale implementation. Although, we are aware of the fast acceptance of petroleum and oil projects but strict rules forced us to do the EIA assay (8). Plasma technology has been employed in developed nations like the EU, Kazakhstan, Russia, Japan, China, as well as the USA for generating energy and lots of other applications (9). It is the right time to take advantage of the present technology for developing other nations. Having looked at studies published, it is hard to find similar studies on TEA of the Plasmatron reactor. So, this study pointed out to similar studies that approached the objectives followed. To estimate the costs of organic rankine cycle systems, the bare module and total module costs have been considered in the framework of equations that estimate the economic aspect of manufactory as an integrated unit with its equipment and facilities (10). Empty fruit bunches, the main residue of the palm oil industry, are assessed to determine the possibility of the bio-oil generation using rapid pyrolysis. The research tried to integrate outlays of total capital investment, specific capital cost, payback period, return on investment, and the product value as a model. Sensitivity analysis was done to compare outlays and variables for the main costs (11). Yuan et al examined and collected a series of technoeconomic equations for the development of shale gas. The model was defined based on the review of techniques and procedures to facilitate the economic evaluation in this regard. The wet and empty fruit bunches of palm oil (400 tons per day) was assessed via energy conversion practices such as bioethanol and jet fuel (by bioconversion), combined heat and power (via gasification), and 
hydrocarbons through fast pyrolysis and bio-oil upgrading (12). The techno-economic model contained input/output model, diagrams, and heat equalization depends on the return on investment, payback period, and internal rate of return (13). Leader et al suggested the use of an economic model to find the outlays of clean technologies of the fuel cell, wind turbine, and lithium batteries considering the materials costs for each technology (14). In another study, the capital cost, operating cost, energy unit cost, the variable cost, effective operating cost, energy recovery cost, fixed cost, interest on capital, capital cost recovery, maintenance cost, total fixed cost, and break-even point were calculated for energy recovery from plastic wastes using plasma technologies in a simple modeling of outlays (15). The variables of economic analysis have been defined by Clark and Rogoff) regarding the cost escalation, interest rate, capital cost, energy cost, operating cost, and maintenance costs in Pro-forma modeling, which can be adjusted slightly and easily for sensitivity analysis (16). In the national area, Iran's economy depends severely on crude oil revenues, comprising approximately $90 \%$ of the total export acquisitions and, on average, $60 \%$ of the government revenues in annual budgets according to the report of the Central Bank of Iran in 2008. Therefore, it is an indispensable matter to protect the national asset and impede spilling and wasting resources, as well as to preserve and protect natural resources. The present study introduced a model to estimate Plasmatron plant costs for generating value-added gaseous products from AS. The requirements of these projects were gathered based on the recent studies and the corresponding author publications in this regard.

\section{Materials and Methods}

In the present study, the TEA falls into the screening step of the EIA program according to Figure 1. The techno- economic modeling was investigated based on the observation, author studies, and experiences.

Plasmatron reactor displayed in Figure 2 in the pilot plant step was designed and configured by Plasma Science and Fusion Center (PSFC) at the Massachusetts Institute of Technology. The requirements of a Plasmatron unit were taken into consideration as shown in Figure 2.

\section{Results}

The EIA as an environmental management instrument encompasses frameworks that underpin many aspects such as environmental audit, life cycle assessment, cumulative impact assessment, ecological impact assessment, environmental quality assessment, and strategic environmental assessment, etc. Environmental audit is a systematic review, periodic and targeted documentation of operation and its equipment related to meeting environmental requirements. Life cycle assessment is a systematic test to determine the environmental impact of a product. The cumulative impact assessment shows different characteristics of the developed western countries compared to the rapidly developing industrialized countries. This assessment identifies the individual impacts of development plans, which can be combined based on the action, reaction, and interconnectedness and have different nature and scope compared to adverse effects. Ecological impact assessment can be a kind of scientific support for the EIA. The ecological surveys identify the habitat where the project site and ambient are located as well as species associated with the habitat. The systematic and dynamic process for assessing environmental quality and consequences are around the developmental milestones, which are realized through policies, programs, and plans $(3,8)$.

To conduct a TEA, the existing properties of the Plasmatron reactor, UMO reprocessing industry, and the

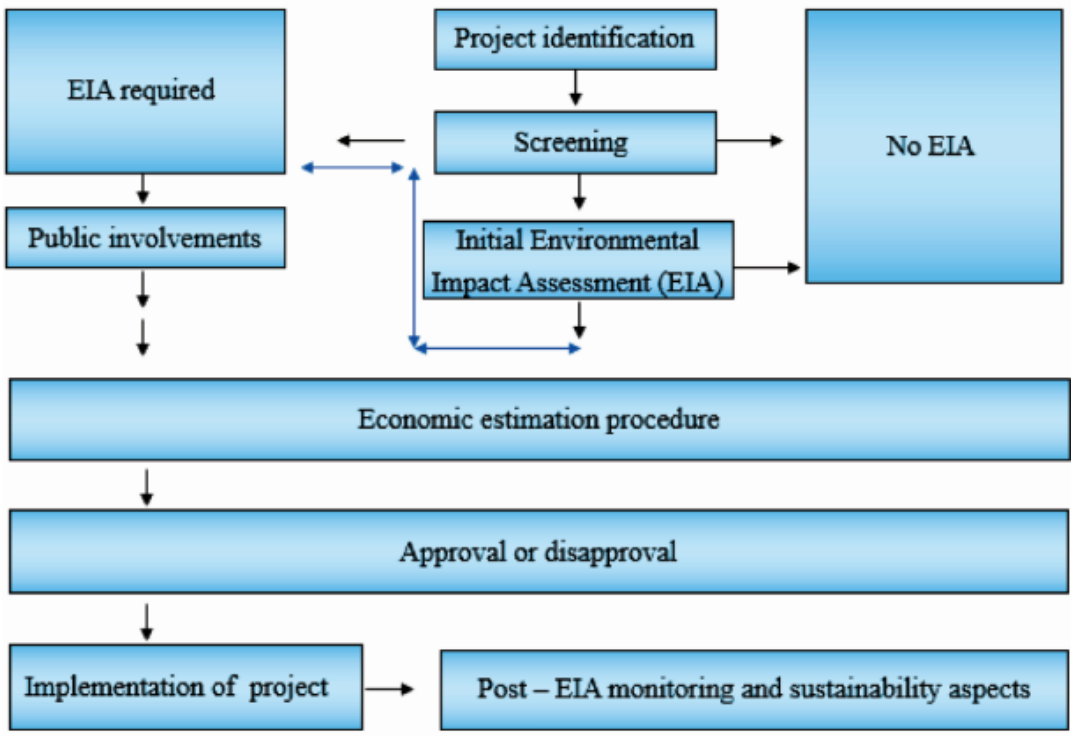

Figure 1. The evaluation steps of the EIA and followed work for the present study. 


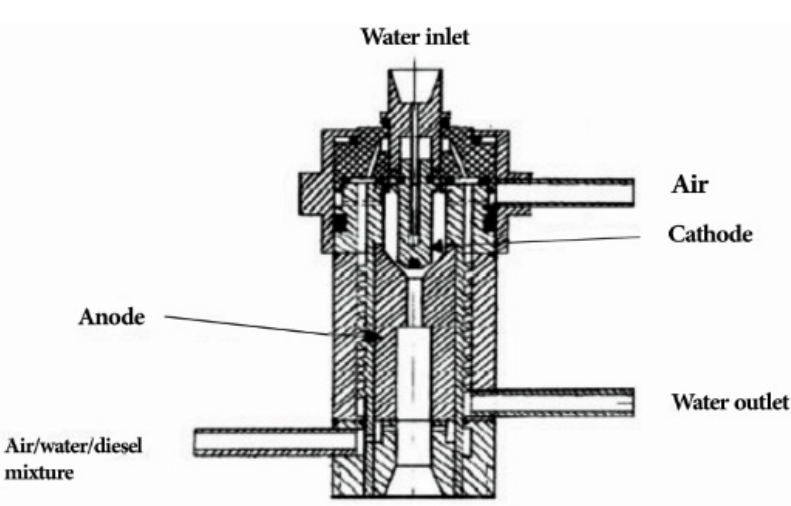

Figure 2. Plasmatron reactor (17).

way that AS is released into the environment should be magnified. Figure 3 shows the process features, technical notes, and operating conditions of a case study of UMO in Iran. The industrial case study retrieves 100 barrels of UMO daily and 15 barrels of AS which is amended to bitumen $54 / 130$ by additives in the author's study (18). Plasma is the most abundant state of matter in the universe in both forms of mass and energy. It has been defined as the fourth state of matter, it occurs when a gas is ionized. Ionized gases mean the presence of free electrons that are not bound to an atom or a molecule. Plasma is electrically conductive and very responsive to electromagnetic fields. The first experiments with plasma were performed to discover the steady-state direct current arc discharge. Plasma is also called the electrically neutral sweeper of the ions and electrons which may or may not contain a background gas that is capable of responding to electric and magnetic fields. Whilst temperature of the ions and neutral particles is usually less than $100^{\circ} \mathrm{C}$, the energy of the electrons in such a plasma corresponds to a temperature about $10000^{\circ} \mathrm{C}$. Thus, they serve as highly reactive instruments for powerful but gentle applications without consumption of high energy. There are two types of plasma namely cold and hot plasma by various reactor configurations. Plasmatron reactor is one of the hot plasma scale-up which has been introduced and gets publicity recently. To configure a Plasmatron reactor in the pilot plant and industrial scales, the requirements of a Plasmatron reactor for converting AS to valuable gaseous product were tabulated (19). Table 1 presents the requirements of a Plasmatron plant for converting AS to value-added gaseous products.

Actually CVD chamber is a different project that will enhance the privileges in full-scale implementation. Table 2 shows the CVD chamber requirements.

The techno-economic model introduced by the following equations include the whole content of Table 1. All requirements were taken into consideration by the equations and integrated the input materials, facilities, and requirements of the project together. Table 3 provides a definition for the symbols of the equations.

$\mathrm{Cbm}=\mathrm{Cp}^{\circ} \times \mathrm{Fbm}$

$\mathrm{Ctm}=1.18 \sum_{i=1}^{n} \mathrm{Cbm}, i$

$\mathrm{Cj}=\left[\sum(M i \times P i)\right] \times\left[\frac{1}{\mathrm{Rj}}\right]$

EIC $=\$_{2}{ }^{a}=D p+5 \%$ of installation cost

$\mathrm{Mc}=\sum \$ 3$

$\mathrm{Pc}=\sum \$ 4$

Gaseous products cost $=\frac{C p j-C r e f}{C F \times M g a s \times 8760}$

$\mathrm{Fc}=\sum \$ 5$

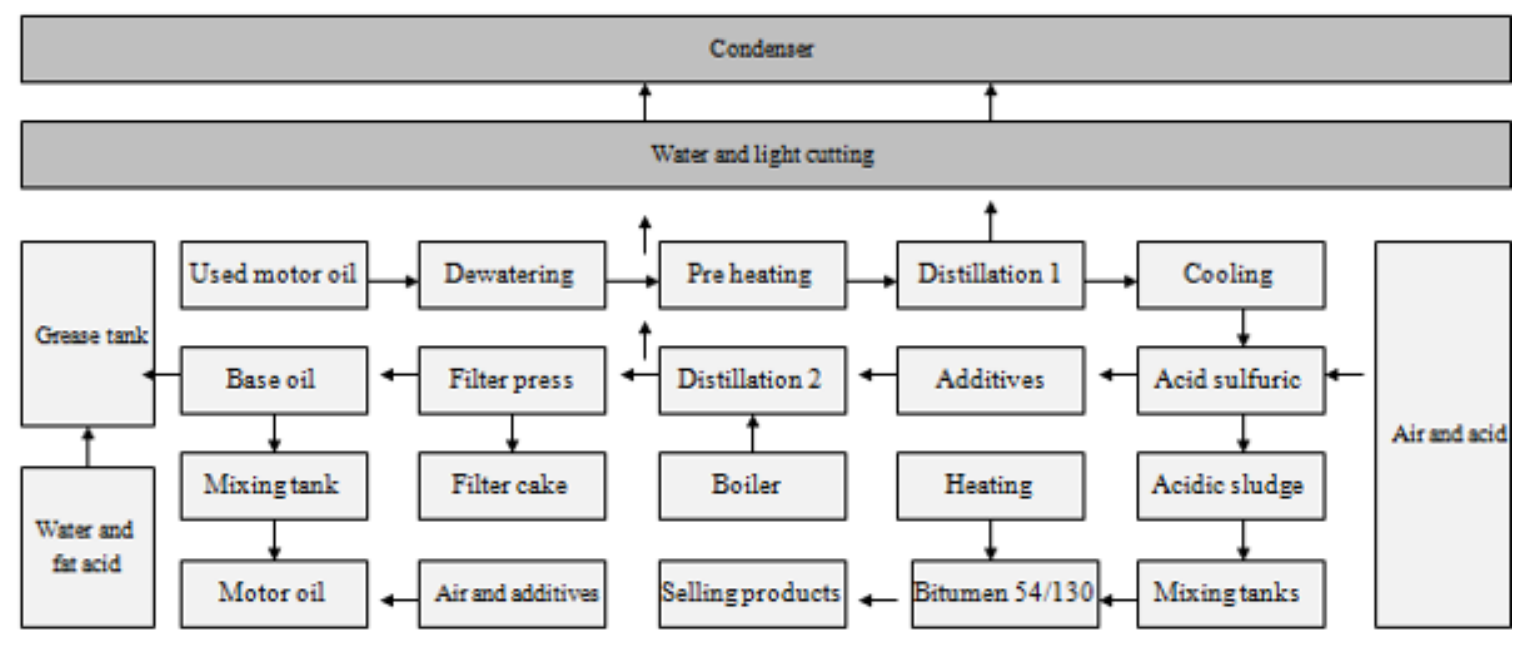

Figure 3. UMO reprocessing industry and AS recycling unit joined (18). 
Table 1. Requirements of a Plasmatron plant for converting AS to value-added gaseous products (17-22)

\begin{tabular}{|c|c|c|c|}
\hline Main Materials and Equipment & Total Rates & \multicolumn{2}{|c|}{ Costs (\$/year) } \\
\hline \multicolumn{4}{|l|}{ Reactor Configuration Costs } \\
\hline Plasmatron gasifier (1000 cm³, combustor plus electrodes) $)^{(a)}$ & 1 No $(17,20)$ & \multirow{9}{*}{$\$ 1$} & \multirow{9}{*}{$2000^{(b)}$} \\
\hline Digital thermometers of reactor & 1 No $(17,20)$ & & \\
\hline Digital manometer (pressure drop) & 1 No $(17,20)$ & & \\
\hline Voltammeter & 1 No $(17,20)$ & & \\
\hline Digital balance & 1 No $(17,20)$ & & \\
\hline Flow meter & 1 No $(17,20)$ & & \\
\hline Tar and chars measuring/analysis equipment (for possible outcome) & $1 \mathrm{No}$ & & \\
\hline Sorbent chamber of silica sand, etc. & 1 No & & \\
\hline Photon beam of laser ${ }^{(c)}$ & 1 No & & \\
\hline \multicolumn{4}{|l|}{ Equipment and Installations Costs } \\
\hline $\mathrm{H}_{2}$ storage tank & 1 No $(17,20)$ & \multirow{7}{*}{$\$ 2^{(d)}$} & \multirow{7}{*}{14000} \\
\hline $\mathrm{CH}_{4}$ storage tank & 1 No $(17,20)$ & & \\
\hline $\mathrm{CO}_{2}$ storage tank & 1 No $(17,20)$ & & \\
\hline $\mathrm{N}_{2}$ storage tank & 1 No $(17,20)$ & & \\
\hline CO storage tank & 1 No $(17,20)$ & & \\
\hline Ash chamber & 1 No & & \\
\hline CVD chamber (c) & 1 No & & \\
\hline \multicolumn{4}{|l|}{ Materials Costs } \\
\hline AS & $891 \mathrm{~m}^{3} /$ year (21) & \multirow{2}{*}{$\$ 3$} & \multirow{2}{*}{ Free } \\
\hline Pure $\mathrm{O}_{2}$ required & Depends & & \\
\hline \multicolumn{4}{|l|}{ Product Costs } \\
\hline $\mathrm{H}_{2}$ yield & $35 \% \operatorname{Vol}(17,20)$ & \multirow{5}{*}{$\$ 4$} & \multirow{5}{*}{ Depends $^{(j)}$} \\
\hline $\mathrm{CH}_{4}$ yield & $89-98 \%$ Vol $(17,20)$ & & \\
\hline $\mathrm{CO}_{2}$ yield & $13 \% \operatorname{Vol}(17,20)$ & & \\
\hline CO yield & $3 \% \operatorname{Vol}(17,20)$ & & \\
\hline $\mathrm{N}_{2}$ yield & $46 \% \operatorname{Vol}(17,20)$ & & \\
\hline \multicolumn{4}{|l|}{ Facilities Costs } \\
\hline Fire extinguishers (total) & 27 No (21) & \multirow{6}{*}{$\$ 5$} & \multirow{4}{*}{5584} \\
\hline Stoves (total) & 3 No $(21)$ & & \\
\hline Cooler (total) & $3 \mathrm{No}(21)$ & & \\
\hline Ventilation system (total) & 7 No $(21)$ & & \\
\hline Office equipment, furniture, etc. & Depends & & 1200 \\
\hline Lab equipment & Depends & & Depends \\
\hline \multicolumn{4}{|l|}{ Transportation Facilities Costs } \\
\hline Transportation (vehicle, car, etc.) & 3 No $(21)$ & $\$ 6$ & 24000 \\
\hline \multicolumn{4}{|l|}{ Employees' Costs } \\
\hline Staff salary & 6 employees (21) & $\$ 7$ & 1200 \\
\hline \multicolumn{4}{|l|}{ Energy Consumption Costs } \\
\hline Required water ${ }^{(\mathrm{e})}$ & $8-13 \%$ Vol $(17,20)$ & \multirow{5}{*}{$\$ 8$} & \multirow{5}{*}{4000} \\
\hline Split AC (internal wiring, transformers, and emergency power generators) & 1 No $(21)$ & & \\
\hline Required electrical energy ${ }^{(f)}$ & $5-20 \mathrm{kw}(20)$ & & \\
\hline Required fuel (stoves) & $1080 \mathrm{~L}(21)$ & & \\
\hline Petroleum costs (transportation vehicle and cars) & $16200 \mathrm{~L}(21)$ & & \\
\hline \multicolumn{4}{|l|}{ Land and Landscaping Costs } \\
\hline Required land & $10000 \mathrm{~m}^{2}(21)$ & & \\
\hline Construction of infrastructure (buildings) & $1142 \mathrm{~m}^{2}(21)$ & & \\
\hline Pavement and asphalt & $2771 \mathrm{~m}^{2}(21)$ & $\$ 9$ & 80000 \\
\hline Landscaping & $1000 \mathrm{~m}^{2}(21)$ & & \\
\hline
\end{tabular}

${ }^{\text {a }}$ Perfectly stirred reactor, mass flow $\sim 5-20 \mathrm{~g} / \mathrm{s}=$ a few hundred liters/minute.

${ }^{\mathrm{b}}$ In a pilot plant scale + CVD reactor.

c It will be taken into account only for deposition purposes.

${ }^{d}$ Daily price $+5 \%$ of the installation cost.

e Initial cost for digging well and its belongings + annual water consumption.

$\mathrm{f} 5 \%$ of the heating value of the hydrogen generated.

${ }^{j}$ It depends on the stockholders preference to produce $\mathrm{CO}+\mathrm{CO}_{2}, \mathrm{H}_{2}+\mathrm{CH}_{4}, \mathrm{CH}_{4}$ or a combination of gases. 


$$
\begin{aligned}
& \mathrm{TFc}=\sum \$ 6 \\
& \mathrm{Ec}=\sum \$ 7 \\
& \mathrm{COE}=\sum \$ 8=\mathrm{CRF} \times \int \mathrm{TPCi}+\int \mathrm{Com}, \mathrm{i}+\mathrm{Cfuel} / \mathrm{CF} \times 8760 \times \mathrm{P} \\
& \mathrm{CRF}(\mathrm{i}, \mathrm{n})=\frac{i \times(1+i)^{n}}{(1+i)^{n}-1} \\
& \mathrm{i}=\mathrm{i} \mathrm{safe}+\mathrm{i} \mathrm{risk}+\mathrm{i} \text { inf } \\
& \mathrm{Ichp}=1.1262 \times 1000000 \times \mathrm{Pe}^{0.7813} \\
& \mathrm{Lc}=\sum \$ 9
\end{aligned}
$$

\section{Discussion}

The $\mathrm{O}_{2}$ exploited for the gasification operation determines the dominant temperature in the operating zone in the reactor. The quantity of $\mathrm{O}_{2}$ employed is estimated as the equivalence ratio (ER) which is the ratio of actual air applied to the stoichiometric quantity of air demanded in combustion operation. Typically, the amount of ER varies for the gasification of biomass and its optimum quantity is around 0.25 . The quantity below the optimum ratio indicates pyrolysis, and the quantity higher than the optimum ER reaches combustion conditions. Therefore,

Table 2. Requirements of diamond CVD chamber (this study)

\begin{tabular}{ll}
\hline Variables & Procedure \\
\hline Temperature & Digital thermometers of reactor \\
\hline Pressure (low, medium, high) & Digital manometer \\
\hline Voltage of power & Voltammeter \\
\hline Gaseous products flow & Flowmeter and GC* \\
\hline Lab facilities & \\
\hline Hardness & X-ray \\
\hline Refractive index & X-ray \\
\hline Dimensions & Microscope SEM and TEM, \\
& Raman spectroscopy, scanning \\
\hline Density & probe microscopy, and cyclic \\
\hline Light indicators & voltammetry \\
\hline Kind of diamond & Empirical equation \\
\hline Blemishes & UV ray \\
\hline Equipment & By instructions \\
\hline Substrate & GIA system instructions \\
\hline CVD & \\
\hline Electrodes & Silicon or molybdenum \\
\hline Substrate holder & Donut-shaped chamber \\
\hline Cooling system & Electrical bias \\
\hline Walls & 1 No \\
\hline Control valves & 1 No \\
\hline Materials required & 1 No \\
\hline Qdditives & Quartz tubes \\
\hline
\end{tabular}

*Gas chromatograph.

**Mixed and separately. the higher the ER, the lower the syngas heating value. However, lower values of ER can also result in high concentrations of tar in the syngas, so tar removal facilities like silica sand absorbents or a rise in power current, etc. are required (23). The hydrogen generation is highly depends on the ratio of $\mathrm{O}_{2}$ and carbon $(\mathrm{C})$ as the highest concentration is achieved by the $\mathrm{O}_{2} / \mathrm{C}$ ratio of $\sim 2$ with higher power demand. Keeping the high power situation with $\mathrm{O}_{2} / \mathrm{C}$ ratio of $<1.6, \mathrm{H}_{2}$ generation efficiency is low $(17,20)$.

In Table 1, the issues associated with land area required, construction of infrastructure (buildings), pavement and asphalt, landscaping, fuel (for stoves) demand, petroleum expenses (vehicles and cars), fire extinguishers (total), stoves (total), cooler (total), and ventilation system (total) were considered as the requirements of a unit of AS (21). The CVD reactor can be coupled with Plasmatron reactor for the deposition purposes especially making up the diamond. Depends on our expectation to produce what kind of diamond, we need to adjust pressure, add some additive materials (considering the gaseous component introduced to CVD/ or separately via gaseous component is possible) and precursors in making up a variety of diamonds such as mono and nano-crystalline diamond films, high-quality diamond, high-quality epitaxial crystals, carbon clusters, nano/micro over-layer framework, diamond-like carbon, epitaxial diamond nucleation, ultrafine diamonds, hexagonal diamond films, and pure diamond. Despite the objectives followed by the present study, the CVD chamber connection was not included but we will take the benefits of exploitation of Plasmatron gasification for further development in this regard. CVD chamber is actually a different project which will enhance the privileges of full-scale implementation (Table 2).

To estimate the costs of the reactor (\$1), Eqs. (1) and (2) can be used. The configured reactor can be considered as the body of a complete module. Total project costs account for direct costs (equipment outlays, materials, and pressures utilized directly for equipment, installation of equipment and facilities, and labor) and indirect costs (freight, insurance, taxes, overhead, and engineering expenses). Total module costs include the unforeseen costs (costs of land and landscaping + facilities costs + reactor configuration costs + transportation facilities cost $=3 \%$ of the investment costs or the total fixed capital and working capital) and contractor fees and additional joining parts and devices. The factor 1.18 varies in a range of 0.18 to 1.18 multiplied by bare module outlays for this kind of project $(10,24)$. It is worth mentioning that bare module cost can be modified by introducing a certain coefficient in adjusting the costs for the pilot plant replaced with the full-scale reactor or any change in the size of the Plasmatron reactor. Thus, the following equations are in connection with Eqs. (1) and (2) in the economic assessment of reactor and unforeseen, direct, 
and indirect costs.

Equation (3) is applied for the deposition purposes in the Plasmatron operation like diamond, graphite and carbon nanotubes, etc. It also determines the costs of precious materials utilized in the Plasmatron reactor configuration (14). The average material intensity $(\mathrm{kg} / \mathrm{kW})$ can be easily found by reviewing literature from related companies such as references (25-28).

The EIC includes Dp of each equipment plus $5 \%$ of its installation cost. The Mc can be calculated via sum of the costs of purchasing both AS and pure $\mathrm{O}_{2}$ required. The pure $\mathrm{O}_{2}$ is required only for a combustor of the reactor and it depends on the type of flame and gas applied for combustion operation. It can be used as an electrical heater or photon beam of the laser without using $\mathrm{O}_{2}$. The materials costs are very low because of refusing AS into the environment and pure $\mathrm{O}_{2}$ availability at low prices everywhere, as presented by Eq. (5). The Pc is sum of gaseous product costs individually, as presented by Eq. (6). Equation 7 shows a certain procedure to estimate the costs of gaseous products individually. According to Table $1, \mathrm{Fc}$ is the outlay for fire extinguishers, stoves, cooler, ventilation system, office equipment, furniture, and a well-equipped lab costs via Eq. (8).

To calculate the costs associated with $\mathrm{H}_{2}, \mathrm{CO}_{2}, \mathrm{~N}_{2}, \mathrm{CH}_{4}$, and $\mathrm{CO}$ yield, Eq. (7) can be employed for any kind of

Table 3. Symbols of the model

\begin{tabular}{|c|c|}
\hline Symbol & Definition \\
\hline $\mathrm{Cp}^{\circ}$ & Base cost \\
\hline $\mathrm{Fbm}$ & $\begin{array}{l}\text { Bare module cost (including operating pressures and particular materials of construction plus direct and indirect project } \\
\text { outlays that can be estimated separately without assuming a factor) }\end{array}$ \\
\hline $\mathrm{Cbm}$ & Bare module outlays \\
\hline Ctm & Project costs defined total module outlay comprising the configured reactor and its belongings as an object or facility \\
\hline $\mathrm{n}$ in equation 2 & The total number of equipment parts \\
\hline j & Clean technology cost \\
\hline i in equation 2 & Valuable element extraction cost \\
\hline C in equation 3 & Total system cost \\
\hline M & The material intensity of each technology \\
\hline $\mathrm{P}$ in equation 3 & Material outlay \\
\hline $\mathrm{R}$ & Ratio of the critical material of technology \\
\hline EIC & Equipment and installations costs \\
\hline $\mathrm{Dp}$ & Daily price \\
\hline Mc & Materials costs \\
\hline Pc & Products cost \\
\hline Fc & Facilities costs \\
\hline C & Annual total cost \\
\hline Mgas & Gas capture rate $\mathrm{kg} / \mathrm{h}$ \\
\hline Subscripts pj & Cogeneration system \\
\hline $\mathrm{CF}$ & Capacity factor (around 0.85) \\
\hline ref & Reference system \\
\hline TFc & Transportation facilities costs \\
\hline Ec & Employee costs \\
\hline COE & The unit cost of energy \\
\hline TPCi & Annual investment cost \\
\hline Com & Annual fixed operation \& maintenance (O\&M) cost \\
\hline i & Discount rate \\
\hline Cfuel & Annual fuel cost \\
\hline$P$ & Plant net energy output (kW) \\
\hline i safe & Safe interest \\
\hline i risk & Risk interest \\
\hline i inf & Inflation rate \\
\hline CRF & Capital recovery factor \\
\hline $\mathrm{n}$ & Plantlife \\
\hline Ichp & Internal combustion engine of the reactor \\
\hline $\mathrm{Pe}$ & Electric capacity (MWe) \\
\hline Lc & Land and landscaping costs \\
\hline
\end{tabular}


gaseous product captured. The reference system can be assumed as a similar and equal system running in a pilot plant or in full-scale plant anywhere else locally. This equation does not include transportation and storage outlay of gaseous products captured (29).

To calculate the TFc, it is important to know, what kind of vehicle are required and how many vehicles do the plants demand. The TFc is calculated using Eq. (9). The Ec is assumed to be the payments for 14 months comprising $23 \%$ of the total salaries for insurance expenses and a daily expenditure for the pensions plus transportation costs per month, for each individual. The mentioned costs must be included in Eq. (10).

The annual fixed operation and maintenance (O\&M) cost in Eq. (11), is assumed to be the total equipment investment $\left(=\sum \$ 9+\sum \$ 5+\sum \$ 1+\right.$ labor costs but regardless of the costs of photon beam of laser and land required) multiplied by an O\&M factor which is usually 0.04 and capacity factor which is assumed to be 0.85 , respectively. To estimate the annual investment cost, the plant investment costs is multiplied by the CRF coefficient which is a function of the discount rate (i) and plant life (n; 30 years or depending on the project lifetime), $i$ safe; determined by the government for the loan interest rate, $i$ risk, and $i$ inf. The isafe, irisk, and $i$ inf are taken into account around $4.2 \%, 3 \%$, and $5 \%$, respectively. The values can be modified with regard to existing conditions locally or nationally. Thus, the CRF is assumed to be exactly about 0.126. In Eq. (11) and in compliance with Eq. (2), TPC is annual investment cost which is calculated by sum of bare module cost and engineering services for provision and construction contractor and contractor fee. In other words, it comprises direct, indirect, and unforeseen costs. The outlays for the Ichp and Pe are calculated by Eq. (14) (30). To calculate the costs of required land and landscaping operation, Eq. (15) is employed. The maintenance costs of facilities, buildings, reactors, landscaping, and etc. are assumed as a certain percentage of the total investment for each item individually like depreciation costs. It will be taken into account after completing the implementation of the project but not in the screening step. In this study, the license fee for plant construction was disregarded because of the very low budget required in comparison with the above-mentioned costs. Due to the vast applications of economic models and equations, the results of the present study are not comparable with other studies. Therefore, similar studies were found in this regard.

The plasma-assisted gasification plant was exploited for conversion of waste to energy with a capacity of 750 tons/day, in Columbia, Canada. The cost estimation was performed based on the labor costs, materials cost, average annual costs of labor, the maintenance cost of the plant and its revenues, cost of plasma arc facilities, etc (31). Dodge tabulated all economic variables of a large plasma plant constructed for gasifying waste and generating renewable fuels through vaporization of garbage (32).
A study tried to use a simple collection of costs to compose the framework of an economic estimation. The cost of installation, equipment cost escalation, engineering expenses, procurement cost, construction cost, construction contractor services costs, total plant cost, process contingency cost, project contingency cost, total overnight cost, owner's costs, total fixed operating cost, and total variable operating cost used to estimate the costs of a plant containing three-reactor chemical looping reforming system to convert hydrocarbon fuels into hydrogen (33). The TEA of biodiesel by soybean refinery was carried out using a model regarding bare module costs to calculate the project costs. By the way, the efficiency and performance of the plant have been estimated by accounting fixed capital expenses, total manufacturing outlay, and key economic parameters (24). Farnoosh used a portfolio model to estimate the costs of power generation plants contain both renewable and fossil fuel technologies with taking into consideration the main elements, technology aim, alternative demands, decision variables, and limitations of the project in Iran (34). The suggested model was defined based on the distribution of average outlays for technologies and standard deviation of costs. The willow was used in phytoextraction operation for remediation of heavy metals from the polluted areas, and then, gasification facilities were employed to the combustion of willow in a safe and healthy way. The techno-economic analysis of the current process was accomplished via cost-benefit analysis and Monte Carlo simulations by considering the mass flow of biomass, mass input flow, moisture content, reactor's thermal capacity of bio-oil, taxes, revenues, expenditure, depreciation, and investment expenditure for the internal combustion engine (30).

Nizami et al tried to provide a TEA model for waste disposal difficulties via waste biorefineries to move towards sustainable waste management and industries development regarding the main economic variables (35). TEA of alternative fuels was performed by tabulating available requirements along with especial equations composing the framework of a model via results of process simulation of product yield, process design, raw materials, utility costs, maintenance and labor expenses, equipment, piping and coupling outlays, and expenditures of service facilities. The aim of the study was to replace fossil-based fuels by green alternatives. But the results could not reach the objective followed due to difficulties in comparison of technology and their methodology (36).

Finally, the application of Plasmatron gasifier was reported by Bromberg et al for natural gas, diesel fuel, and heavy hydrocarbons reformation (17). Although they used metal catalysts to raise the efficiency of Plasmatron in producing gaseous products but recent studies have investigated the gasification operation regardless of using metal catalysts and similar efficiency of Plasmatron in producing gaseous products has been reported. For this reason, the present 
study reduced the use of catalysts as one of the project requirements. It has been reported as a cost-effective technology in reformation operation (37).

\section{Conclusion}

To the best of our knowledge, this is the first study that used TEA of the Plasmatron reactor for managing AS of reprocessing industries in Iran. The present study arranged the framework of TEA to include a full inventory of the availability of the Plasmatron reactor and its CVD chamber for the deposition aim. The Plasmatron reactor was identified as a dominant and overwhelming technology to reduce the challenges experienced in managing the AS released. The economic model introduced, facilitated the evaluation of financial efficiency in the screening step of the EIA. Further studies are recommended to investigate the performance assessment of plants (Plasmatron plants) based on data envelopment analysis. Also, the expansion in the way of economic model maturation is highly recommended. The energy balance, green materials, and energy exploitations to run and conduct the reactor also claim lots of models to define and develop. According to the results of this study, simplicity in the economic model and its outcome are taken into consideration a lot. The coincidence of the tabulated variables with the objective followed in the equations integrated various chains of the model together. Finally, the techno-economic model paved the way towards sustainable development of the current reactor and UMO units in industrial scale-up in Iran.

\section{Acknowledgments}

This research is a part of the author's Ph.D. research work, entitled "Evaluation of 405 Iranian Industries". Any opinions, findings, and conclusions expressed in this publication are those of the author and do not necessarily reflect the current views and policies.

\section{Ethical issues}

The author hereby certifies that all data collected during the study are as stated in the manuscript, and no data from the study has been or will be published separately elsewhere.

\section{Competing interests}

The author declares that he has no competing interests.

\section{Authors' contributions}

The author contributed and is involved in the suggestion of the problem, design of research, data collection, and approval of the final manuscript.

\section{References}

1. Hassanpour M, Jonidi Jafari A, Gholami M, Farzadkia M. Feasibility study of recycling and converting acidic sludge to bitumen in used motor oil refining industries. Journal of Health in the Field 2013; 1(2): 44-52. doi: 10.22037/jhf. v1i2.5152. [In Persian].

2. Zhang W. Techno-Economic Analysis (TEA) and Environmental Impact Assessment (EIA) of Corn Biorefinery and Bioprocessing Operation [dissertation]. Ames, Iowa: Iowa State University; 2017.

3. Jonidi Jafari A, Hassanpour M. Analysis and comparison of used lubricants, regenerative technologies in the world. Resour Conserv Recycl 2015; 103: 179-91. doi: 10.1016/j. resconrec.2015.07.026.

4. Hatami AM, Sabour MR, Amiri A. Recycling process of spent bleaching clay: optimization by response surface methodology. Glob J Environ Sci Manag 2018; 4(1): 9-18. doi: 10.22034/gjesm.2018.04.01.002.

5. Asgari A, Nabizadeh R, Mahvi AH, Nasseri S, Dehghani $\mathrm{MH}$, Nazmara S, et al. Biodegradation of total petroleum hydrocarbons from acidic sludge produced by re-refinery industries of waste oil using in-vessel composting. J Environ Health Sci Eng 2017; 15: 3. doi: 10.1186/s40201017-0267-1.

6. Hadadi V, Moradi A. A novel method for refining of acidic sludge and mixing with vacuum bottom to improve bitumen properties. Pet Sci Technol 2019; 37(13): 1529-38. doi: 10.1080/10916466.2019.1573258.

7. Alavi SE, Abdoli MA, Khorasheh F, Bayandori Moghaddam A. Non-isothermal pyrolysis of used lubricating oil and the catalytic effect of carbon-based nanomaterials on the process performance. J Therm Anal Calorim 2020; 139(2): 1025-36. doi: 10.1007/s10973-019-08436-w.

8. Munn RE. Environmental Impact Assessment: Principles and Procedures. New York: John Wiley and Sons; 1979.

9. Yazicioğlu Ö, Katircioğlu YT. Applications of plasma technology in energy sector. Yazıcıoğlu \& Katırcıoğlu / Kirklareli University Journal of Engineering and Science 2017; 3: 18-44.

10. Lemmens S. Cost engineering techniques and their applicability for cost estimation of organic Rankine cycle systems. Energies 2016; 9(7): 485. doi: 10.3390/en9070485.

11. Do TX, Lim YI, Yeo H. Techno-economic analysis of biooil production process from palm empty fruit bunches. Energy Convers Manag 2014; 80: 525-34. doi: 10.1016/j. enconman.2014.01.024.

12. Yuan J, Luo D, Feng L. A review of the technical and economic evaluation techniques for shale gas development. Appl Energy 2015; 148: 49-65. doi: 10.1016/j. apenergy.2015.03.040.

13. Do TX, Lim YI. Techno-economic comparison of three energy conversion pathways from empty fruit bunches. Renewable Energy 2016; 90: 307-18. doi: 10.1016/j. renene.2016.01.030.

14. Leader A, Gaustad G, Babbitt C. The effect of critical material prices on the competitiveness of clean energy technologies. Mater Renew Sustain Energy 2019; 8(2): 8. doi: 10.1007/s40243-019-0146-z.

15. Nema SK, Ganeshprasad KS. Plasma pyrolysis of medical waste. Curr Sci 2002; 83(3): 271-8.

16. Clark BJ, Rogoff MJ. Economic feasibility of a plasma arc gasification plant, city of Marion, Iowa.Proceeding of the 18th Annual North American Waste-to-Energy 
Conference; 2010 May 11-13; Orlando, Florida, USA; 2010. doi: 10.1115/ nawtec18-3502.

17. Bromberg L, Alexeev N. Plasma Assisted Reforming of Methane: Two Stage Perfectly Stirred Reactor (PSR) Simulation. Massachusetts: Massachusetts Institute of Technology; 2005.

18. Jonidi Jafari A, Hassanpour M. Survey of economic indices of the used motor oil industry equipped to acidic sludge recycling unit (a case study). Merit Research Journal of Engineering, Pure and Applied Sciences 2014; 2(2): 22-9.

19. Unnisa SA, Hassanpour M. Development circumstances of four recycling industries (used motor oil, acidic sludge, plastic wastes and blown bitumen) in the world. Renew Sustain Energy Rev 2017; 72: 605-24. doi: 10.1016/j. rser.2017.01.109.

20. Bromberg L, Cohn DR, Rabinovich A, Alexeev N. Hydrogen Manufacturing Using Low Current, Non-Thermal Plasma Boosted Fuel Converters. San Diego, CA: Proceedings of the Symposium on Energy for the 21st Century: Hydrogen Energy, Sponsored by the Fuel Chemistry Division of the American Chemical Society; 2001.

21. Jonidi Jafari A, Hassanpour M, Farzadkia M. Economic evaluation of recycling acidic sludge project of reprocessing industries to bitumen (a case study). Environ Technol Innov 2016; 5: 30-40. doi: 10.1016/j.eti.2015.11.004.

22. Dutch Association of Cost Engineers (DACE). DACE Price Booklet. 32th ed. The Netherlands: DACE; 2017. p. 1-26.

23. Mohamed AH. Process Intensification in Syngas Production and Cleaning [dissertation]. Great Britain: University of Newcastle Upon Tyne; 2013.

24. Granjo JF, Duarte BP, Oliveira NM. Integrated production of biodiesel in a soybean biorefinery: modeling, simulation and economical assessment. Energy 2017; 129: 273-91. doi: 10.1016/j.energy.2017.03.167.

25. Argus Media Group. ARGUS Rare Earths Analytics. [cited 2019 Jan 7] Available from: https://www.argusmedia.com/ en/metals/argus-rare-earths-monthly-outlook.

26. Mining Dot Com. Commodity Closing Prices. [cited 2018 Jul 25] Available from: https://www.mining.com/markets/.

27. USGS. Rare Earths Statistics and Information. [cited 2018 Sep 16] Available from: https://minerals.usgs.gov/minerals/
pubs/commodity/rare_earths/myb1-2011-raree.pdfUSGS.

28. USGS. Lithium Statistics and Information. [cited 2019 Oct 24] Available from: https://www.usgs.gov/centers/nmic/ lithium-statistics-and-information.

29. Li S, Jin H, Gao L, Zhang X, Ji X. Techno-economic performance and cost reduction potential for the substitute/ synthetic natural gas and power cogeneration plant with CO2 capture. Energy Convers Manag 2014; 85: 875-87. doi: 10.1016/j.enconman.2013.12.071.

30. Kuppens T, Cornelissen T, Carleer R, Yperman J, Schreurs $\mathrm{S}$, Jans $\mathrm{M}$, et al. Economic assessment of flash co-pyrolysis of short rotation coppice and biopolymer waste streams. J Environ Manage 2010; 91(12): 2736-47. doi: 10.1016/j. jenvman.2010.07.022.

31. Ducharme C. Technical and economic analysis of Plasmaassisted Waste-to-Energy processes [dissertation]. New York City: Columbia University; 2010.

32. Dodge ED. Plasma Gasification of Waste: Clean Production of Renewable Fuels through the Vaporization of Garbage. Ithaca, New York: Cornell University; 2008. p. 51.

33. Khan MN, Shamim T. Techno-economic assessment of a plant based on a three reactor chemical looping reforming system. Int J Hydrogen Energy 2016; 41(48): 22677-88. doi: 10.1016/j.ijhydene.2016.09.016.

34. Farnoosh A. On the Economic Optimization of National Power Generation Mix in Iran: A Markowitz PortfolioBased Approach. France: IFP; 2016. [In French].

35. Nizami AS, Rehan $M$, Waqas $M$, Naqvi $M$, Ouda OK, Shahzad K, et al. Waste biorefineries: enabling circular economies in developing countries. Bioresour Technol 2017; 241: 1101-17. doi: 10.1016/j.biortech.2017.05.097.

36. Albrecht FG, König DH, Baucks N, Dietrich R-U. A standardized methodology for the techno-economic evaluation of alternative fuels - a case study. Fuel 2017; 194: 511-26. doi: 10.1016/j.fuel.2016.12.003.

37. Wong MS, Lu CA, Chang HK, Yang TS, Wu JH, Liou Y. Diamond synthesis via $\mathrm{C}] \mathrm{H}$ metal precursors processed in hot filament chemical vapor deposition and microwave plasma chemical vapor deposition. Thin Solid Films 2000; 377-378: 274-9. doi: 10.1016/S0040-6090(00)01327-4. 